\title{
TOUCH AND MASSAGE ON LABOR PAIN INTENSITY DURING FIRST STAGE OF ACTIVE PHASE
}

\author{
Irna Susanti ${ }^{1 *}$, Dewi Anggraini ${ }^{2}$, Ari Purwaningsih ${ }^{3}$ \\ 1,2 Universitas Muhammadiyah Jakarta \\ ${ }^{3}$ Koja Public Hospital Jakarta \\ Email*: irnanursanti.fik@gmail.com
}

\begin{abstract}
Introduction: Labor pain is a challenging issue for nurses designing intervention protocols. Touch and massage therapy is one of non-pharmacology approaches that they could do during labor process. The study was conducted to assess the effectiveness in reducing pain intensity scale on the labor during first stage of active phase. Methods: A quasi-experimental approach was conducted and a purposive sampling technique was used to recruit 56 women who expected to have normal childbirth at a public hospital in Jakarta, Indonesia. They randomly assigned to either received touch and massage intervention (experiment) or not (control). The labor pain intensity was using Verbal Description Scale (VDS) with descriptive statistics, paired, and independent t-test. Results: The result showed that touch and massage therapy had a significant impact on the experimental group $\left(t_{c a l} I 2.839, p<0.05\right)$. A significant difference also showed among the experimental dan control group during pre-test $\left(t_{\text {cal }}^{I} 1.817, p>0.05\right)$ and post-test $\left(t_{c a l}^{I} 10.77, p<0.05\right)$. The study found that a combination of touch and massage therapy was effective to reduce labor pain during active stage. Conclusions: Touch and massage therapy can reduce labor pain intensity, and at the same time serve as closeness and encouragement during the first stage of active phase. It is a cost-effective nursing intervention and can positively influence the quality of women's birth experiences.
\end{abstract}

Keywords: first stage active phase; labor pain; massage; touch

\section{INTRODUCTION}

Labor pain is a physiological and natural process during normal childbirth that leaves stressful and fears experience for some women (Gibson, 2014; Roberts et al., 2010). A study from Ternström et al., 2016 found that most women in their study worry, often with negative feelings and fear, about labor pain. Besides, a study reported that $63 \%$ of mothers did not get information about self-preparation through labor pain. Women who suffered uncontrolled labor pain can trigger some physical changes, such as an increase in cardiac output (50-150\%), an increase in blood pressure of $40 \%$, and postpartum depression potential (11-30\%) (AM et al., 2016).

Several analgesics to reduce the pain can be used, but side-effects and non-medical factors on women indicate that analgesia alone may not manage the pain comprehensively (Chang et al., 2002; Sai et al., 2019). Selfcomforting from nurses during the labor process is also needed to manage labor pain (Chang et al., 2002). Thereby, some nonpharmacological treatments to reduce labor pain that nurse can initiate are touch and massage.

Touch and massage on the back can release muscle spasms especially in women who experience back pain during pregnancy. Several studies reported that light touch techniques can help normalize heart rate and blood pressure. This technique includes light touch and massage that can make fine hairs on a standing skin surface. Several studies also showed that this technique massage can distract labor pain and stimulate endorphins and increases the release of endorphins (Gibson, 2014; Gönenç \& Terzioğlu, 2020; Roberts et al., 2010). It can be done by nurse independently because it does not need oil or any instruments (Smith et al., 2018). However, most of the hospitals in Indonesia do not implement any non-pharmacological therapy to reduce labor pain or discomfort.

There appears to be renewed interest in the use of touch and massage in nursing and little study has been undertaken to examine the effects of massage on women in labor. Hence, we felt the need and planned to give a combination of those non-pharmacological 
measures, touch and massage, and assess its effectiveness in reducing the intensity of labor pain during the first stage of active phase in Indonesia.

\section{METHODS}

The study design adopted was quasiexperimental (pre and post-test control group design). The population included in this study was pregnant women at a regional public hospital in Jakarta, Indonesia. The inclusion criteria were: 1) pregnant women $\geq 18$ years, 2) indicated to give birth normally, 3 ) did not use any pharmacological therapy to reduce pain, 4) did not experience paralysis or nerve disorders in certain body parts, 5) no injuries and/or bruises on the skin, as well as the skin disease being suffered. Samples were screened based on inclusion criteria validated by medical records, then researchers began offering their ability to participate in this study. Ethical consideration approval was obtained from the institutional review board (IRB) of a teaching hospital in northern Jakarta, Indonesia.

We used a purposive sampling technique to recruit 60 women and divided them into experimental and control group 30 women each. Four experimental group respondents dropped out in the middle of the study. Thereby, only 26 respondents in the experimental group can be analyzed. Inform consent and demographic questionnaire were fulfilled by respondents before the study began. Pre and post-test were documented in the observation sheet filled by the researcher to determine the intensity scale before and after the intervention.

Touch and massage were held on the respondent's bed in a comfortable position, whether sitting or lying on her side, and then we asked them to breathe deeply. The intervention was started by stroking the outer surfaces of the respondent's arms alternately, starting from the hands to the forearms. This touch is done gently and done using fingers or just the tips of the fingers so that the respondent can immediately feel calm. The next step was back massage from neck. Light massage was done in the shape of the letter $\mathrm{V}$ towards side of the rib cage to lower back. Researchers also create the atmosphere with motivating words during the massage, such as "When I massage your arms, you can try to relax your body and release the pain you have suffered." Some respondents also seemed to relax easily with spiritual or religious pray that they believe to reduce the pain.

We gave touch and massage therapy for about 5 minutes and only once within the first stage of active phase before delivery process began. Then we measured the level of labor pain intensity in post-test session. The pre and post-test observation sheet using the Verbal Description Scale (VDS) for pain intensity. VDS has simple scores: 1-3 mild pain, 4-6 moderate pain, 7-9 controlled severe pain, and 10 uncontrolled severe pain. During measurement, respondents mentioned how much pain was felt from 1 to 10 , so researchers can compare scores on the two results. The data were analyzed using frequency percentage, paired t-test, and independent t-test.

This study was conducted in the giving birth room of Koja Hospital, Jakarta. A research ethics permit was obtained from Koja Hospital (No: 41/I/DKT-2019).

\section{RESULTS}

Fifty-six women in labor were included in the study. The experimental group consisted of 26 women. Most respondents in both experimental and control group were in 20-35 years old (61\% and 57\%), had 12-years of education (65\% and 53\%), and unemployed (88\% and $93 \%)$ (Table 1). 
Table 1. Distribution of samples according to demographic characteristics ( $\mathrm{n}=56)$

\begin{tabular}{clcccc}
\hline Variables & Categories & \multicolumn{2}{c}{$\begin{array}{c}\text { Experimental } \\
\text { Group }\end{array}$} & \multicolumn{2}{c}{$\begin{array}{c}\text { Control } \\
\text { Group } \\
\text { n= 26 }\end{array}$} \\
\cline { 3 - 6 } & & $\mathbf{f}$ & $\mathbf{3 0}$ & $\mathbf{f}$ & \% \\
\hline Age in & $<20$ year & 4 & 15.4 & 2 & 6.6 \\
years & 20-35 year & 16 & 61.5 & 17 & 56.6 \\
& $>$ 35 year & 6 & 23.1 & 11 & 36.8 \\
\hline Education & Elementary & 3 & 11.5 & 2 & 6.6 \\
& Junior & 4 & 15.4 & 9 & 30 \\
& High & 17 & 65.4 & 16 & 53.3 \\
& University & 2 & 7.7 & 3 & 10 \\
\hline \multirow{2}{*}{ Employee } & Housewife & 23 & 88.5 & 28 & 93.3 \\
& Work & 3 & 11.5 & 2 & 6.7 \\
\hline Ethnicity & Java & 10 & 38.5 & 5 & 16.6 \\
& Sunda & 4 & 15.4 & 3 & 10 \\
& Betawi & 11 & 42.3 & 15 & 50 \\
& Other & 1 & 3.8 & 7 & 23.4 \\
\hline \multirow{2}{*}{ Religion } & Islam & 25 & 96.2 & 27 & 90 \\
& Christian & 1 & 3.8 & 3 & 10 \\
\hline
\end{tabular}

Table 2. Comparison of VDS for pain intensity in the experimental group using paired t-test $(\mathrm{n}=26)$

\begin{tabular}{cccccc}
\hline & Mean (SD) & Mean Difference & Min-Max & t & p \\
\hline Pre & $8.96(1.41)$ & & $6-9$ & & \\
\cline { 1 - 1 } Post & $6.73(1.27)$ & 2.23 & $4-8$ & 2.84 & 0.001* \\
\hline *significant $\mathrm{p}<0.05$ & & & &
\end{tabular}

Table 3. Comparison of VDS for pain intensity between experimental group and control group using independent $\mathrm{t}$-test $(\mathrm{n}=56)$

\begin{tabular}{clcccc}
\hline \multicolumn{1}{c}{ Groups } & Mean (SD) & $\begin{array}{c}\text { Mean } \\
\text { Difference }\end{array}$ & t & p \\
\hline \multirow{3}{*}{ Pre } & Experimental $(\mathrm{n}=26)$ & $8.96(1.41)$ & 0.76 & 1.82 & 0.69 \\
\cline { 2 - 3 } & Control $(\mathrm{n}=30)$ & $8.60(1.15)$ & & & \\
\hline \multirow{3}{*}{ Post } & Experimental $(\mathrm{n}=26)$ & $6.73(1.27)$ & 2.07 & $\mathbf{1 0 . 7 2 *}$ & $\mathbf{0 . 0 0 1 *}$ \\
\cline { 2 - 3 } & Control $(\mathrm{n}=30)$ & $8.80(1.33)$ & & & \\
\hline
\end{tabular}

*significant $\mathrm{p}<0.05$

Table 2 shows an average scale of labor pain during the first stage active phase. The VDS of pain in pre-test was 8.96 and a standard deviation was 1.612. Meanwhile, it became 6.73 during post-test with the standard deviation was 1.991 . The pain score range before the intervention was between 6 and 9 , but there was a decreased range became 4 to 8 in post-test. The paired t-test result (Table 2) also shows a significant reduction of labor pain at 0.001 level of significance after touch and massage therapy.

In Table 3 below, there were differences in pain scale before and after touch and massage therapy. However, there was no 
decrease according to mean and SD value in the control group.

\section{DISCUSSIONS}

Touch and massage therapy is believed to be a simple, safe, and effective method to relieve labor pain during childbirth. According to a study from Tzeng and colleagues (2017), women in reproductive age tend to have unstable psychological conditions and anxiety which occurred at the high pain level. Chang et al. (2002) also commented that in medical field the use of touch and massage therapy such as effleurage, stroking, and pressure in specific areas could facilitate women's ability to cope with labor. In keeping with earlier work (Chang et al., 2002), comforting touch was found to be significant and important. This finding differed from that in a study in Hong Kong (Holroyd et al., 1997), which reported that China people use distance to regulate their privacy and level of intimacy in encounters. However, the result of our study suggests that, although cultural, ethnic, and religious differences exist between Eastern and Western societies, the perception of nursing behaviors by Indonesian women is able to tolerate the touch and massage as a therapy.

The combination of touch and massage therapy within decreasing level of labor pain during the first stage of active phase in this study was in accordance with the Gate Control Theory by Melzack and Wall (1965). The Gate Control Theory explains that pain will be felt when pain impulses or stimuli from the source of pain are successfully delivered by nerve fibers to the central nervous system (brain) treatment center through the treatment gate (pain gate). The gate can be closed by activating $A \beta$ nerve fibers through the stimulation of touch, pressure, touch, or vibration given during pain so that the impulse of pain is not transmitted to the spinal cord and also to the brain and allows all that cannot be imagined well. When the pain gate is open, pain stimulation can be delivered to the brain so that pain can be felt (Moayedi \& Davis, 2013). The touch and massage therapy is one of the ways to block the pain gate so the stimuli cannot reach through the nervous system. In addition, affection and supportive words from nurse during the touch and massage therapy will give a positive feeling which also can reduce the pain (Holroyd et al., 1997).

Of the non-pharmacological methods, touch and massage is a noninvasive technique for promoting relaxation and improving communication with women in labor. Most of the respondents could not express their feelings. It only appeared from their facial expression and gestures. Although the pain did not disappear completely, respondents showed that touch and massage therapy make them relax gradually. They said the most comfortable part was back massage, especially in the coccyx area. In order to find an effect over and above the presence of a supportive person, the control group was to some extent placebo controlled, in that the person doing and teaching massage was present and made conversation with control couples but did not actively intervene.

\section{CONCLUSIONS}

This study elucidates the effect of combination between touch and massage on labor pain intensity, especially during the first stage of active phase. The technique is important for women to improve a sense of comfort and calm before and during the labor process. It can also create a distraction so the discomfort will reduce automatically. Consequently, massage has the potential to improve the relationship between nurses/midwives and woman in labor, as well as between the couple.

By considering the variables and analysis in this study were not various, we suggest the future researchers may wish to add more variables, such as measuring vital signs or fetal heart rate before and after the 
intervention or temperature and environment support in the delivery room. The psychological condition of women who accompanied by family during first stage active phase or the utilization of certain oils and aromatherapy are also worth to do to get a strengthen result.

\section{ACKNOWLEDGEMENT}

The authors are grateful for the Association of Indonesian Nurse Education Centers (AIPNI-AINEC), Faculty of Nursing Muhammadiyah University of Jakarta, Lembaga Penelitian dan Pengabdian Masyarakat (LPPM) Muhammadiyah University of Jakarta, Koja Public Hospital for its support of this study. Also, thank you for all respondents for cooperation during the process.

\section{REFERENCES}

AM, H., SK, B., SK, B., \& IS, K. (2016). Insomnia During Pregnancy: Diagnosis and Rational Interventions. Pakistan Journal of Medical Sciences, 32(4), 1030-1037. https://doi.org/10.12669/pjms.324.10421 LK http://bj7rx7bn7b.search.serialssolutions. com?sid=EMBASE \&issn=1682024X\&id $=$ doi:10.12669\%2Fpjms.324.10421\&atitl $\mathrm{e}=$ Insomnia+during+pregnancy $\% 3 \mathrm{~A}+\mathrm{Dia}$ gnosis+and+rational+interventions\&stitle $=$ Pak. + J.+Med. + Sci.\&title $=$ Pakistan + Jou rnal+of+Medical + Sciences $\&$ volume $=32$ \&issue $=4 \&$ spage $=1030 \&$ epage $=1037 \& a$ ulast $=$ Hashmi\&aufirst=Ali+M.\&auinit $=$ A.M.\&aufull=Hashmi+A.M.\&coden=PJ MSC\&isbn $=\&$ pages $=1030$ 1037\&date $=2016 \&$ auinit $1=$ A\&auinitm $=$ M.

Chang, M.-Y., Wang, S.-Y., \& Chen, C.-H. (2002). Effects of massage on pain and anxiety during labour: a randomized controlled trial in Taiwan. Journal of Advanced Nursing, 38(1), 68-73. https://doi.org/10.0000/13504859435787
1

Gibson, E. (2014). Women's expectations and experiences with labour pain in medical and midwifery models of birth in the United States. Women and Birth, 27(3), 185-189.

https://doi.org/10.1016/j.wombi.2014.05. 002

Gönenç, I. M., \& Terzioğlu, F. (2020). Effects of Massage and Acupressure on Relieving Labor Pain, Reducing Labor Time, and Increasing Delivery Satisfaction. The Journal of Nursing Research: JNR, 28(1), e68. https://doi.org/10.1097/jnr.00000000000 00344

Holroyd, E., Yin-king, L., Pui-yuk, L. W., Kwok-hong, F. Y., \& Shuk-lin, B. L. (1997). Hong Kong Chinese women's perception of support from midwives during labour. Midwifery, 13(2), 66-72. https://doi.org/10.1016/S02666138(97)90058-9

Moayedi, M., \& Davis, K. D. (2013). Theories of pain: From specificity to gate control. Journal of Neurophysiology, 109(1), 512. https://doi.org/10.1152/jn.00457.2012 Roberts, L., Gulliver, B., Fisher, J., \& Cloyes, K. G. (2010). The Coping With Labor Algorithm: An Alternate Pain Assessment Tool for the Laboring Woman. Journal of Midwifery and Women's Health, 55(2), 107-116. https://doi.org/10.1016/j.jmwh.2009.11.0 02

Sai, C. Y., Mokhtar, N., Yip, H. W., Bak, L. L. M., Hasan, M. S., Arof, H., Cumming, P., \& Mat Adenan, N. A. (2019). Objective identification of pain due to uterine contraction during the first stage of labour using continuous EEG signals and SVM. Sadhana - Academy Proceedings in Engineering Sciences, 44(4). https://doi.org/10.1007/s12046019-1058-4

Smith, C. A., Levett, K. M., Collins, C. T., Dahlen, H. G., Ee, C. C., \& Suganuma, M. (2018). Massage, reflexology and 
Touch and Massage on Labor Pain Intensity ... (Susanti, et.al)

other manual methods for pain management in labour. Cochrane Database of Systematic Reviews, 2018(3).

https://doi.org/10.1002/14651858.CD009 290.pub3

Ternström, E., Hildingsson, I., Haines, H., \& Rubertsson, C. (2016). Pregnant women's thoughts when assessing fear of birth on the Fear of Birth Scale. Women and Birth, 29(3), e44-e49. https://doi.org/10.1016/j.wombi.2015.11. 009

Tzeng, Y. L., Yang, Y. L., Kuo, P. C., Lin, Y. C., \& Chen, S. L. (2017). Pain, anxiety, and fatigue during labor: A prospective, repeated measures study. Journal of Nursing Research, 25(1), 59-67. https://doi.org/10.1097/jnr.00000000000 00165 